\title{
CORRESPONDENCE.
}

\section{ON THE CALCULATION OF SURVIVORSHIP PREMIUMS.}

\author{
To the Editor of the Journal of the Institute of Aetuaries.
}

SIR,-I write to you at the suggestion of Mr. T. B. Sprague, who thinks that the subject of some correspondence $I$ have recently had with him on the approximate calculation of premiums for survivorship assurances may perhaps interest the readers of the Journal.

The actuary of a life office is sometimes called upon to quote premiums for survivorship assurances where several lives are concerned, e.g., the premium for an assurance payable in the event of the death of the last survivor of $A, B, C, D, \ldots$ occurring in the lifetime of $X$. The single premium for an assurance of the kind last mentioned would usually be small in amount, and methods of approximation are sometimes resorted to to form a rough estimate of its value. Great caution has to be exercised in using methods of approximation for the caleulation of assurance premiums or other actuarial functions. The subject of probabilities is one, as I think, affording unusual facilities for error, especially when applied to the calculation of monetary benefits dependent upon life. Take an instance:-An approximate method sometimes, I believe, employed for the calculation of an assurance premium such as that mentioned above is the following : Let $p, q, r, s, \ldots$ represent the separate probabilities of the lives $A, B, C, D, \ldots$ predeceasing $X$; then as a rough estimate take the product $p q v s .$. as the value of the probability that all the lives $\mathbf{A}, \mathbf{B}, \mathrm{C}, \mathrm{D}, \ldots$ will predecease $\mathbf{X}$.

If we practically load the premium by assuming that money makes no interest, then we obtain the expression pqrs.... as the office single premium to be charged for the risk. As an example, suppose there are six lives $A, B, C, D, E$, and $F$, each aged 39 , and that $X$ is also aged 39. Then $p q r s t u=\left(\frac{1}{2}\right)^{6}=\frac{1}{64}=015625$, so that the office single premium would be $£ 1.11 s .3 d$. per $\$ 100$ assured. Assuming the correctness of the process for finding the probability of the event, it is obvious that a very heavy loading is imposed in this particular case by neglecting the effect of interest, since six lives all under middle age must drop before a claim can arise.

The product $p q r$ stu does not of course give the exact probability of the event, since the events whose separate probabilities are $p, q, r, s, t$ and $u$ are not independent. Further it will be seen that the result is not even approximately correct. The required probability is that of $X$ dying last of the seven lives, and as the lives are all supposed to be of the same age this probability is evidently $\frac{3}{7}$, which is about nine times as great as the value obtained above.

I have calculated by the method exemplified by $\mathrm{Mr}$. King (J.I.A., xxvi, 276), taking the $\mathrm{H}^{\mathrm{I}}$ mortality table and 4 per-cent 
interest, the single premium for the above assurance, supposed payable at the instant of the death of $X$. The integral for summation is

$$
\frac{1}{l_{x} x^{7}} \int v^{t}\left(l_{x}-l_{x+t}\right)^{6} l_{x+t} \mu_{x+t} d t
$$

and adopting 8 as the interval $h$, I arrived at the result 0274 , or £2. 14 s. 10 d. per $£ 100$ assured, for the unloaded premium. The mode of conducting the calculations permits of the probability of the six lives $A, B, C, D, E$, and $F$, predeceasing $X$ being arrived at by $a$ little additional work. I obtained the result 1486 , which is about 4 per-cent in excess of the true value, namely, $\frac{1}{7}$ or 1429 .

If the sum assured be payable at the instant of the risk being determined, i.e., upon the death of the last survivor of the six lives $A, B, C, D, E$, and $F$ in the lifetime of $X$, the integral for summation will be

$$
\frac{6}{l_{x} x^{7}} \int v^{t}\left(l_{x}-l_{x+t}\right)^{5} l_{x+\frac{2}{t}} \mu_{x+t} d t
$$

Adopting the same assumption as to age as in the former case, and applying the above method of summation, -1544 is obtained as the approximate value of the probability (the true value being 1429 as before), and 0833 as the single premium at $H^{\mathbf{M}} 4$ per-cent. Mr.H.J. Rothery informs me that the application of Mr. Woolhouse's summation formula, "Nugget No. 1 " (J.I.A., xxvii, 151), gave 1554 for the probability and 0337 for the single premium, for the assurance payable when the risk determines.

\section{I am. Sir,}

Your obedient servant,

2, King Willam Street,

A. W. SUNDERLAND.

Liondon, E.C.

1 January 1889.

\section{PAYMENT TO TRUSTEES.}

To the Editor of the Journat of the Institute of Actuaries.

SIR,--In the XXVIth Volume of the Journal of the Institute, pages 134-149, will be found reports of the cases In re Bellamy and In re Flower and the Metropolitan Board of Works. In the first of these eases it was decided in effect that trustees had no power to delegate, to a person outside of their own number, the collection of money due to them, and, in the second, that trustees could not delegate such collection to one of themselves. By these decisions, the 56th Section of "The Conveyancing and Law of Property Act, 1881 ", by which it was enacted that the production by a solicitor of 